Running head: PREJUDICE, INTERGROUP CONTACT AND BREXIT

\title{
Examining the Role of Positive and Negative Intergroup Contact and Anti-Immigrant Prejudice in Brexit
}

\author{
Rose Meleady \\ Charles R. Seger \\ Marieke Vermue
}

School of Psychology, University of East Anglia, UK

Word Count: 3371(excluding References and Tables and Figures)

\begin{abstract}
Author Note
Correspondence regarding this article should be sent to Rose Meleady at the University of East Anglia, School of Psychology, Norwich, NR4 7TJ, UK. Tel: +441603 591760. Email: r.meleady@uea.ac.uk. The authors declare that there are no potential conflicts of interest with respect to the research, authorship, and/or publication of this article.
\end{abstract}




\begin{abstract}
This study examined the interplay of anti-immigrant prejudice and intergroup contact experience on voting intentions within Britain's 2016 referendum on its membership within the European Union. In the days before the referendum we asked more than 400 British people how they planned to vote. We measured a number of demographic factors expected to predict voting intentions as well as individuals' prejudice toward, and intergroup contact experience (positive and negative) with EU immigrants. Anti-immigrant prejudice was a strong correlate of support for Brexit. Negative intergroup contact experience was associated with higher antiimmigrant prejudice and, in turn, increased support for 'Leave'. Positive intergroup contact, on the other hand, seemed to play a reparative role, predicting lower prejudice and increasing support for 'Remain'.
\end{abstract}

Keyword: PREJUDICE, INTERGROUP CONTACT, EU REFERENDUM, VOTING INTENTIONS 


\section{Examining the Role of Positive and Negative Intergroup Contact and}

\section{Anti-Immigrant Prejudice in Brexit}

On the 23rd of June 2016 the UK Government held a nationwide referendum to decide whether Britain should 'Remain' within, or 'Leave' the European Union (EU). Turnout was a high $72.2 \%$, with more than 30 million people voting. Of this, a majority of $51.9 \%$ voted to leave the EU. The result, which sent shockwaves through the country, is particularly notable as it is the first time in history that a member state has voted to quit the EU. It has been argued in the popular media that 'Brexit' was propelled by anti-immigrant prejudice. In this paper we empirically test this claim, and further explore the role played by individuals' intergroup contact experience. It was expected that the frequency with which individuals actually come into contact with immigrants would also be an important predictor of voting intentions. Importantly, we distinguish between positive and negative intergroup encounters, and examine the independent impact of both types of contact within this novel and important real-world context.

Immigration is not a recent phenomenon in Britain, yet it continues to be at the forefront of both political discourse and public debate. A 2012 poll showed that $68 \%$ of the British public believed that immigration has a negative effect on Britain (YouGov, 2012). Another demonstrated that $57 \%$ thought tension between immigrants and people born in Britain was a leading cause of societal division (Ipsos MORI, 2012). The free movement of people is one of the founding principles of the European Union. EU citizens are entitled to live, work and study within any other EU member state. The popular perception that this system encourages an inflow of migrants to Britain without apparent control, particularly from the EU's poorer nations, has made EU immigrants a prime target for discrimination and racially motivated violence in the UK (Blinder, 2011; 2015, Burnett, 2011). 
The campaign to leave the EU was accused of stirring these feelings and "fanning the flames of division" in a bid to win the referendum (Cowburn, 2016). Referred to as 'Project Hate' by the Remain camp, the Leave campaign focused heavily on the topic of immigration, arguing that levels of EU migration had become too high and that Britain needs to leave the EU to cut immigration. The slogan 'we want our country back', became a powerful rallying cry, portraying immigrants as an enemy who needs to be expelled. One campaign poster featuring a queue of migrants and calling for Britain to take back control of its boarders was reported to the police for inciting racial hatred and breaching UK Race Relations law. Shortly thereafter a former chair of the Conservative Party quit the Leave campaign citing its "hateful and xenophobic" tactics (Elgot, 2016). In this study, we sought to establish the extent to which antiimmigrant prejudice contributed to support for 'Brexit' amongst voters.

Interestingly, commentators have noted an apparent paradox whereby the more immigrants live in an area, the less likely people in that area were to vote in favour of leaving the EU (Goodwin \& Heath, 2016). Voting figures show that the highest levels of Remain voters were found in districts with high net migration, while some of the strongest Leave districts were those which have seen the fewest immigrants. For example, in Lambeth in London, which recorded the highest proportion of Remain votes, people born outside of the UK account for $38.8 \%$ of the population. Meanwhile in Great Yarmouth in Norfolk, immigrants account for just $6.6 \%$ of the population, but $71.5 \%$ of residents voted to Leave. Taken across all districts, areas with a lower than average proportion of people born outside the UK recorded a majority vote for Leave in $85 \%$ of cases, while districts with a higher than average proportion of immigrants voted to Leave in just $44 \%$ of cases (Lawton \& Ackrill, 2016).

These figures suggest a possible role for intergroup contact in voting decisions. Intergroup contact occurs when members of different cultural groups interact and come to 
know each other across group lines (Allport, 1954). This integration of social groups has been shown to powerfully reduce prejudice between them. Since Allport's original formation, over 500 studies have confirmed that there is a fundamental and robust negative correlation between intergroup contact and prejudice (Pettigrew \& Tropp, 2006). This effect replicates across different implementations, participant populations and bases for group membership (for reviews see Al Ramish \& Hewstone, 2013; Hewstone \& Swart, 2011; Pettigrew \& Tropp, 2011). It may be then, that people living in areas with a high concentration of immigrants were more favourable towards Remain due to the increased opportunity for intergroup contact with this group. Of course, opportunities for intergroup contact should not be conflated with actual contact and do not necessitate that individuals will choose to engage in meaningful interactions with other groups (Hewstone, 2015, see also Christ et al., 2014). Accordingly, in this research we go beyond previous analyses of voting outcomes that rely on aggregate-level data of the proportion of immigrants living in an area by studying (self-reported) individual-level contact experience. It is expected that individuals with greater personal contact experience with EU immigrants will show lower prejudice towards this group and therefore be more inclined to vote 'Remain'.

Another important consideration concerns the valence of intergroup contact. In much of the existing literature the word 'contact' is treated as synonymous with 'positive contact' or 'intergroup friendship'. The emphasis on using intergroup contact to improve intergroup relations has led to the exclusion of negative contact from most research designs (Pettigrew, 2008; Pettigrew \& Tropp, 2006). While it is now beyond any doubt that positive contact reduces prejudice, research has only recently begun to examine the potential for negative contact to increase prejudice. Emerging results suggest that while people tend to report more frequent positive contact, negative episodes of intergroup contact can have independent, detrimental effects on outgroup attitudes (e.g. Barlow et al., 2012; Dhont \& Van Hiel, 2009; 
Graf, Paolini, \& Rubin, 2014; Hayward, Tropp, Hornsey, \& Barlow, 2017; Reimer et al., 2017). These recent findings highlight the importance of recognising positive and negative experiences as related but separate dimensions of intergroup contact. In the study we sought to apply this distinction by simultaneously examining the association between positive and negative intergroup contact and voting intentions within the referendum. In contrast to positive contact effects, negative contact experiences may be expected to confirm or enhance antiimmigrant prejudice and, in doing so, push voters towards Leave.

\section{The Present Research}

The Brexit debate was dominated by the topic of immigration, with the Leave campaign accused on triumphing on the back of anti-immigrant prejudice. This study provides the first empirical test of the association between prejudice and support for Brexit. Importantly, we also explored the contribution of intergroup contact experience. A mediational pathway was expected in which intergroup contact experience would predict voting intentions via its effects on prejudice. Drawing on recent advancement in intergroup contact theory we examined the independent association between both positive and negative intergroup contact and voting intentions. Negative intergroup contact was expected to be associated with heightened prejudice, and increased intentions to vote 'Leave', in turn. Positive contact, on the other hand, was expected to be associated with reduced prejudice and increased intentions to vote 'Remain'.

\section{Participants}

\section{Method}

The study was conducted on the $14^{\text {th }}$ and $15^{\text {th }}$ of June $2016^{1}$. A community sample of 448 participants was recruited via an online participant panel (Prolific Academic). Participants received a small payment in exchange for their participation. Only British participants over the 
age of 18 were eligible to take part. We asked participants if they had registered, and if they planned to vote in the upcoming EU referendum. An a priori decision was made to only include those participants who answered 'yes' to both questions. The sample size was chosen with the aim of collecting 400 usable participants. The final sample consisted of 417 participants, $(58 \%$ female, 1 not reported $)$ aged between 18 and $66\left(M_{\mathrm{age}}=34.98, \mathrm{SD}_{\mathrm{age}}=\right.$ $11.78)^{2}$

\section{Procedure}

The study was described as a survey on current events. Participants were told that they would answer questions regarding their attitudes towards the EU, and EU immigrants. We clarified that by 'EU immigrant' we meant someone who has come to live in Britain from another country within the EU. The order of all scales was counterbalanced, and a number of filler items were included to mask our hypotheses.

Quantity of positive intergroup contact, and quantity of negative intergroup contact were measured as two independent dimensions with single items adapted from Barlow and colleagues (2012). In contrast to traditional measures of contact valence where positive and negative contact are treated as opposite ends of the same continuum, this approach recognizes that these experiences are not mutually exclusive but that people but may report high levels of both forms of contact, low levels of both, or any combination of the two. Quantity of positive contact was measured with the item 'On average, how frequently do you have positive/good contact with EU immigrants?', and quantity of negative contact with the item 'OOn average, how frequently do you have negative/bad contact with EU immigrants?" with participants responding on seven-point scales $(1=$ never, $7=$ extremely frequently $)$.

To assess prejudice, we used a feeling thermometer (Haddock, Zanna, \& Esses, 1993) which asked participants to indicate how cold (unfavourable) or warm (favourable) they feel towards EU immigrants, in general, on a scale from $0^{\circ}$ to $100^{\circ}$. Feeling thermometers have 
been widely used in intergroup relations research and provide a less reactive measure of prejudice than those which explicitly ask participants whether they endorse negative statements about outgroup members (e.g. McConahay, 1986). To ease interpretation, the scale was reverse coded such that higher values indicate higher levels of prejudice.

To measure voting intentions participants were asked how they planned to vote in the upcoming EU referendum on a five-point scale $(1=$ definitely Remain, $2=$ leaning Remain, $3=$ undecided, 4 = leaning towards Leave, 5 = definitely Leave). Finally, participants provided demographic information. Pre-referendum public opinion polls placed age, education, political orientation and gender among the most important correlates of voting choice (YouGov, 2016). We measured each of these variables here. Participants indicated their highest level of education from $1=$ GSCEs or less to $5=$ doctoral degree and placed themselves on a political spectrum from $1=$ very liberal to $7=$ very conservative.

\section{Results}

Pearson product-moment correlations were conducted to examine the correlations between all variables. These are presented in Table 1 with means and standard deviations. A paired samples $t$-test indicated that people engaged in positive contact with EU immigrants more frequently $(M=4.13, \mathrm{SD}=1.71)$ than they engaged in negative contact with $\mathrm{EU}$ immigrants $(M=2.55, \mathrm{SD}=1.40), t(416)=13.59, p<.001, d=1.01$.

[insert Table 1 here]

A hierarchical regression analysis was then conducted to examine the extent to which prejudice and intergroup contact predicted voting intentions over and above standard demographic predictors (including political conservatism). Demographic factors were entered as control variables in Step 1, and prejudice and intergroup contact (positive and negative) were entered in Step 2. As gender did not show a bivariate correlation with voting intentions it was not included in the regression analysis. The remaining demographic factors explained a 
significant amount of variance in voting intentions (see Table 2). Examination of the coefficients revealed that older voters, those with less formal education, and a more conservative political orientation expressed greater intentions to vote Leave.

Importantly, the inclusion of prejudice and intergroup contact in Step 2 provided a significant amount of additional explained variance. As expected, individuals reporting greater prejudice towards EU immigrants were more inclined to vote Leave. Positive and negative contact also had significant, independent effects on voting intentions. More positive contact with EU immigrants predicted a stronger intention to vote Remain, while more negative contact with EU immigrants predicted a stronger intention to vote Leave.

[insert Table 2 here]

A mediational analysis was then conducted to examine the extent to which the association between intergroup contact (positive and negative) and voting intentions was accounted for by changes in prejudice towards EU immigrants. The analysis was conducted using bootstrapped mediation tests of the indirect effect of intergroup contact on voting intentions through prejudice (based on 5,000 bootstrapped resamples) using Hayes' (2013) PROCESS macro (Model 4). An adaption to this model was used which allows for multiple predictor variables. Our model therefore simultaneously estimated the indirect effects of the two independent variables (through the same mediator) in a single model, rather than testing two separate models for each independent variable. Demographic factors were included as covariates. The results supported our mediation hypothesis. Positive intergroup contact was predictive of intentions to vote Remain, through reductions in prejudice (indirect effect $=-.11$, $95 \% \mathrm{CI}=-.1797$ to -.0571$)$. Meanwhile, negative contact was predictive of intentions to vote Leave, through increases in prejudice (indirect effect $=.08,95 \% \mathrm{CI}=.0430$ to .1323 ). Full path estimates are displayed in Figure 1. 
[insert Figure 1 here]

\section{Discussion}

The present findings provide the first empirical support for the presumed role of antiimmigrant prejudice in Britain's decision to leave the EU. Prejudice towards EU immigrants was found to be a powerful predictor of support for Brexit. Importantly however, intergroup contact experience also played an important role. Intergroup contact theorists have long established that anti-immigrant prejudice is reduced when members of the national majority group have positive interactions with immigrants (e.g. Binder et al., 2009; Pettigrew, 1997; Pettigrew, Wagner, \& Christ, 2010; Voci \& Hewstone, 2003). Here, we demonstrate that as a consequence of its prejudice-reducing effects, positive intergroup contact was associated with increased support for Britain remaining in the EU. This finding provides an important illustration of the contact hypothesis at work and helps explain the seemingly counterintuitive observation that areas with low proportions of immigrants were those most likely to vote Leave.

Of course, living in an area that experiences high levels of migration also affords the opportunity for negative encounters with outgroup members. Previous examinations of the effect of negative intergroup contact are limited, meaning that the contemporary understanding of intergroup contact is biased towards positive factors and positive consequences. Here, we simultaneously examined both forms of contact. Though negative contact was found to be less prevalent than positive contact (consistent with previous findings, e.g. Barlow et al., 2012; Graf et al., 2014; Hayward et al., 2017), it played an important, independent role in voting intentions. As anticipated, negative contact experience was associated with increased prejudice towards EU immigrants and thereby increased support for Britain to leave the EU.

The present findings further highlight the importance of simultaneously considering negative contact when examining the benefits of positive contact, and extends the growing 
literature on negative contact by demonstrating that it not only worsens intergroup attitudes, but may also motivate behavioural responses, in this case, with important political ramifications. Evidence of the impacts of negative intergroup contact does not dispute the merits of positive intergroup contact, but rather invites a full understanding of intergroup contact effects. It will be important for future research to continue to investigate negative intergroup contact and understand the full range of its attitudinal and behavioural consequences. It will be important also to understand what drives this prejudice-enhancing effect of negative contact. Emerging findings suggest that negative contact may not simply be the reverse of positive contact, but may be driven by different mediating processes (e.g. anger, resentment or fear; Barlow et al., 2012; Hayward et al., 2017).

Importantly, the role of prejudice and intergroup contact in voting intentions is evidenced here after controlling several important demographic variables. We observed, in this sample, that older voters, less educated voters, and more politically conservative voters were those more inclined to vote to Leave the EU. This latter effect of political orientation was particularly strong. Prejudice and intergroup contact were then found to represent further predictors of voting intentions, over and above this standard toolkit of demographic predictors. Interestingly, we also observed a correlation between intergroup contact and political orientation where political conservatism is associated with lower reporting of positive contact and higher reporting of negative contact. The reasons for this are unclear. It is possible that conservatives have less opportunity for positive contact with members of other groups, or are more likely to perceive contact as negative when it does occur. Alternatively, it could be the case that intergroup contact may have the potential to promote more flexible, liberal belief structures (see Crisp \& Turner, 2011). This represents another interesting avenue for future research. 
Some limitations of the present study should be acknowledged. First, the data is crosssectional and thus we cannot make any firm conclusions regarding causality. The causal impact of intergroup contact has previously been evidenced in longitudinal (e.g. Binder et al., 2009; Paolini, Harwood, \& Rubin, 2010) and experimental tests (e.g. Ensari \& Miller, 2002; Paolini et al., 2014), and we interpreted our findings accordingly. However, it may be the case that the reverse pathway is also at work in which contact experience with EU is used as a post hoc rationalization for participants' voting preferences. Further, for pragmatic reasons, intergroup contact experience (positive and negative) was measured with single item measures. These items were taken from previous contact investigations where their predictive validity has been established (e.g. Barlow et al., 2012). As such, we do not believe them to pose a serious problem in this study. However, we did observe a very strong correlation between intergroup contact (particularly positive contact) and prejudice, which could indicate that without using items that provide concrete examples of what constitutes positive and negative contact (see Reimer et al., 2017, for instance) participants may simply project their attitudes towards immigrants when reporting how positive or negative their experiences have been with this group. Nevertheless, the fact that the indices of prejudice and contact explained unique variance in voting intentions goes some way to alleviate concerns that they are measuring the same construct.

Although we limited our sample to participants who intended to cast a vote in the referendum, we do not have a measure of how participants ultimately voted. In our crosssectional design, we opted to focus on measuring intentions prior to the referendum rather than post hoc reports of voting behavior due to the difficulty of measuring actual behavior in a secret ballot, and the tendency for respondents to overstate support for the winning side after an election (e.g., Atkeson, 1999; Wright 1990). It is still possible however, that participants' voting behaviour may differ from their stated intentions. Additionally, although our sample is 
much more diverse than traditional student samples, it was not a nationally representative sample. Our intention was not, however, to conduct an opinion poll but rather, to test the theoretical mechanisms underlying voting preferences. Nevertheless, we cannot confirm that the mechanisms observed here will generalize to the entire voting population.

Britain's decision to leave the EU will no doubt be a topic for much further enquiry. Whilst this study considered the role of prejudice and intergroup contact as drivers of voting intentions, it will be important for future research to also consider how the outcome of the referendum may impact intergroup relations. Britain has experienced a spike in racially motivated hate crimes following the referendum (National Police Chief's Council, 2016). It remains to be seen what lasting effect Brexit may have on intergroup hostilities and animosities, especially when it may mean that opportunities for intergroup contact are less readily available. 


\section{Notes}

${ }^{1}$ The data collection took place before the murder of MP Jo Cox which many commentators connected to referendum campaigning.

${ }^{2}$ No changes in the pattern or significance of results are found if we use the full data set which includes people who had not registered, or did not plan to vote $(N=448)$. 


\section{References}

Al Ramiah, A., \& Hewstone, M. (2013). Intergroup contact as a tool for reducing, resolving and preventing intergroup conflict: Evidence, limitations, and potential. American Psychologist, 68, 527-542. doi: 10.1037/a0032603

Allport G. W. (1954). The nature of prejudice. Cambridge, MA: Addison-Wesley

Atkeson, L. R. (1999). "Sure, I voted for the winner!" Overreport of the primary vote for the party nominee in the national election studies. Political Behavior, 21, 197-215. doi:10.1023/A:1022031432535

Barlow, F.K., Paolini, S., Pederson, A., Hornsey, M.J., Radke, H.R., Harwood, J...Sibley, C.G. (2012). The contact caveat: Negative contact predicts increased prejudice more than positive contact predicts reduced prejudice. Personality and Social Psychology Bulletin, 38, 1629-1643. doi: 10.1177/0146167212457953

Binder, J., Zagefka, H., Brown, R., Funke, F., Kessler, T., Mummendey, A., . . Leyens, J.-P. (2009). Does contact reduce prejudice or does prejudice reduce contact? A longitudinal test of the contact hypothesis amongst majority and minority groups in three European countries. Journal of Personality and Social Psychology, 96, 843-856. doi: $10.1037 / \mathrm{a} 0013470$

Blinder, S. (2011). UK public opinion towards immigration: Determinants of attitudes. Migration Observatory Briefing Paper, University of Oxford. Retrieved from http://www.migrationobservatory.ox.ac.uk/wp-content/uploads/2016/04/BriefingPublic_Opinion_Determinants_of_Attitudes.pdf

Blinder, S. (2015). UK public opinion towards immigration: Overall attitudes and level of concern. Migration Observatory Briefing Paper, University of Oxford. Retrieved from http://www.migrationobservatory.ox.ac.uk/wp-content/uploads/2016/04/BriefingPublic_Opinion_Overall_Attitudes_and_Level_of_Concern.pdf 
Burnett, J. (2011). Eastern European workers under attack. Institute of Race Relations. Retrieved from http://www.irr.org.uk/news/eastern-european-workers-under-attack/

Crisp, R.J., \& Turner, R.N. (2010). Adaptation to the experience of social and cultural diversity. Psychological Bulletin, 137, 242-266. doi: 10.1037/a0021840

Christ, O., Schmid, K., Lolliot, S., Swart, H., Stolle, D., Tausch, N...Hewstone, M. (2014). Contextual effects of positive intergroup contact on outgroup prejudice. Proceedings of the National Academy of Sciences, 111 (11), 3996-4000. doi: 10.1073/pnas.1320901111

Cowburn (2016, June 6). EU Referendum: Brexit campaign accused of 'fanning the flames of division' with controversial map. Retrieved from:

http://www.independent.co.uk/news/uk/politics/eu-referendum-vote-leave-accused-offanning-the-flames-of-division-after-publishing-controversial-a7067701.html

Dhont, K., \& Van Hiel, A. (2009). We must not be enemies: Interracial contact and the reduction of prejudice among authoritarians. Personality and Individual Differences, 46, 172-177. doi: 10.1016/j.paid.2008.09.022

Elgot, J. (2016, June 20). Sayeeda Warsi quits leave campaign over 'hateful, xenophobic' tactics. Retrieved from: http://www.theguardian.com/politics/2016/jun/20/sayeedawarsi-quits-leave-campaign-over-hateful-xenophobic-tactics

Ensari, N. \& Miller, N. (2002). The outgroup must not be so bad after all: The effects of disclosure, typicality, and salience on intergroup bias. Journal of Personality and Social Psychology, 83, 313-329. doi: 10.1037/0022-3514.83.2.313

Goodwin, M.J., \& Heath, O. (2016) The 2016 Referendum, Brexit, and the left behind: An aggregate-level analysis of the result. The Political Quarterly, 87, 323 -332. doi: 10.1111/1467-923X.12285

Graf, S., Paolini, S., \& Rubin, M. (2014). Negative intergroup contact is more influential, but positive intergroup contact is more common: Assessing contact prominence and contact 
prevalence in five Central European countries. European Journal of Social Psychology, 44, 536-547. doi: 10.1002/ejsp.2052

Haddock, G., Zanna, M.P., \& Esses, V.M. (1993). Assessing the structure of prejudicial attitudes. The case of attitudes towards homosexuals. Journal of Personality and Social Psychology, 65, 1105-1118. doi: 10.1037/0022-3514.65.6.1105

Hayes, A.F. (2013). Introduction to mediation, moderation, and conditional process analysis: A regression-based approach. New York: Guildford Press.

Hayward, L.E., Tropp, L.R., Hornsey, M.J., \& Barlow, K. (2017). Towards a comprehensive understanding of intergroup contact: Descriptions and mediators of positive and negative contact among majority and minority groups. Personality and Social Psychology Bulletin, 43, 347-364. doi: 10.1177/0146167216685291

Hewstone, M. (2015). Consequences of diversity for social cohesion and prejudice: The missing dimension of intergroup contact. Journal of Social Issues, 71, 417-438. doi: $10.1111 /$ josi.12120

Hewstone, M. \& Swart, H. (2011). Fifty-odd years of inter-group contact From hypothesis to integrated theory. British Journal of Social Psychology, 50, 374-386. doi: 10.1111/j.2044-8309.2011.02047.x

Ipsos MORI (2012). British Future - State of the Nation 2012/3. Retrieved from https://www.ipsos-mori.com/Assets/Docs/Polls/BritishFuture_2013_topline.PDF Lawton, C., \& Ackril, R. (2016). Hard evidence: How areas with low immigration voted mainly for Brexit. The Conversation. Retrieved from http://theconversation.com/hardevidence-how-areas-with-low-immigration-voted-mainly-for-brexit-62138

McConahay, J.B. (1986). Modern racism, ambivalence, and the modern racism scale. In J.F. Dovidio \& S.L. Gaertner (Eds.), Prejudice, discrimination, and racism (pp. 91-125). New York, NY: Academic Press. 
National Police Chief's Council (2016). Unity and respect needed, not hate crime. Retrieved from: http://news.npcc.police.uk/releases/sara-thornton-blog-unity-and-respect-needednot-hate-crime-30-june-2016

Paolini, S., Harwood, J., \& Rubin, M. (2010). Negative intergroup contact makes group memberships salient: Explaining why intergroup conflict endures. Personality and Social Psychology Bulletin, 36, 1723-1738. doi: 10.1177/0146167210388667

Paolini, S., Harwood, J., Rubin, M., Husnu, S., Joyce, N., \& Hewstone, M. (2014). Positive and extensive intergroup contact in the past buffers against the disproportionate impact of negative contact in the present. European Journal of Social Psychology, 44, 548-562. doi: 10.1002/ejsp.2029

Pettigrew, T. F. (1997). Generalized intergroup contact effects on prejudice. Personality and Social Psychology Bulletin, 23, 173-185. doi: 10.1177/0146167297232006

Pettigrew, T.F. (2008). Future directions for intergroup contact theory and research. International Journal of Intercultural Relations, 32, 187-199. doi: 10.1016/j.ijintrel.2007.12.002

Pettigrew, T.F., \& Tropp, L.R. (2006). A meta-analytic test of intergroup contact theory. Journal of Personality and Social Psychology, 90, 751-783. doi: 10.1037/00223514.90.5.751

Pettigrew, T.F., \& Tropp, L.R. (2011). When groups meet: The dynamics of intergroup contact. Philadelphia, PA: Psychology Press.

Pettigrew, T.F., Wagner, U., \& Christ, O. (2010). Population ratios and prejudice: Modelling both contact and threat effects. Journal of Ethnic and Migration Studies, 36, 635-650. doi: 10.1080/13691830903516034

Reimer, N. K., Becker, J. C., Benz, A., Christ, O., Dhont, K., Klocke, U., ... Hewstone, M. (2017). Intergroup contact and social change: Implications of negative and positive 
contact for collective action in advantaged and disadvantaged groups. Personality and Social Psychology Bulletin, 43, 121-136. doi: 10.1177/0146167216676478

Voci, A. \& Hewstone, M. (2003). Intergroup contat and prejudice towards immigrants in Italy: The mediational role of anxiety and the moderational role of group salience. Group Processes and Intergroup Relations, 6, 37-54. doi: 10.1177/1368430203006001011

Wright, G. C. (1990). Misreports of vote choice in the 1988 NES senate election study. Legislative Studies Quarterly, 543-563.

YouGov (2016, June 21). Introducing the YouGov referendum model. https://yougov.co.uk/news/2016/06/21/yougov-referendum-mode

YouGov (2012). YouGov / Sunday Times Survey Results. Retrieved from: http://cdn.yougov.com/cumulus_uploads/document/d51j2t3jzl/YG-Archives-Pol-STresults-06-080112.pdf 
Table 1

Correlations and descriptive statistics for all variables.

\begin{tabular}{|c|c|c|c|c|c|c|c|c|c|}
\hline & $\begin{array}{c}\mathrm{M} \\
(S D)\end{array}$ & 1 & 2 & 3 & 4 & 5 & 6 & 7 & 8 \\
\hline (1) Voting intention & $\begin{array}{c}2.51 \\
(1.62)\end{array}$ & - & & & & & & & \\
\hline (2) Age & $\begin{array}{c}34.99 \\
(11.79)\end{array}$ & $.15^{* *}$ & - & & & & & & \\
\hline (3) Gender & $\begin{array}{c}0.42 \\
(0.49)\end{array}$ & .002 & $-.14 * *$ & - & & & & & \\
\hline (4) Education & $\begin{array}{c}2.75 \\
(0.99)\end{array}$ & $-.17 * * *$ & .02 & -.02 & - & & & & \\
\hline $\begin{array}{l}\text { (5) Political } \\
\text { conservatism }\end{array}$ & $\begin{array}{c}3.33 \\
(1.62)\end{array}$ & $.43^{* * *}$ & $.16^{* *}$ & .02 & $-.14 * *$ & - & & & \\
\hline (6) Prejudice & $\begin{array}{c}34.29 \\
(26.14)\end{array}$ & $.51 * * *$ & -.14 & .08 & $-.17 * * *$ & $.43^{* * *}$ & - & & \\
\hline (7) Positive contact & $\begin{array}{c}4.13 \\
(1.71)\end{array}$ & $-.40 * * *$ & $-.15^{* *}$ & -.02 & $.23 * * *$ & $-.34 * * *$ & $-.59 * * *$ & - & \\
\hline (8) Negative contact & $\begin{array}{c}2.55 \\
(1.40)\end{array}$ & $.34 * * *$ & .01 & $.10^{*}$ & -.04 & $.22 * * *$ & $.46^{* * *}$ & $-.17 * * *$ & - \\
\hline
\end{tabular}

Note: Higher scores for voting intention indicate a preference for Leave.

Gender: $0=$ female, $1=$ male. 
Table 2

Hierarchical regression analysis predicting intention to vote Leave from demographic factors, prejudice towards, and contact with EU immigrants.

\begin{tabular}{|c|c|c|c|c|c|c|}
\hline & $\beta$ & $t$ & $\mathrm{sr}^{2}$ & $F$ & $R^{2}$ & $\Delta R^{2}$ \\
\hline \multicolumn{7}{|l|}{ Variable } \\
\hline Step 1 & & & & $35.09 * * *$ & .20 & - \\
\hline Age & .09 & $2.10 *$ & & & & \\
\hline Education & -.12 & $-2.65 * *$ & & & & \\
\hline Political Conservatism & .40 & $8.78 * * *$ & & & & \\
\hline Step 2 & & & & $36.36 * * *$ & .35 & $.15^{* * *}$ \\
\hline Age & .07 & 1.56 & .06 & & & \\
\hline Education & -.06 & -1.56 & .06 & & & \\
\hline Political Conservatism & .22 & $4.93 * * *$ & .19 & & & \\
\hline Prejudice & .25 & $4.33 * * *$ & .17 & & & \\
\hline Positive Contact & -.13 & $-2.52 * *$ & .10 & & & \\
\hline Negative Contact & .15 & $3.32 * *$ & .13 & & & \\
\hline
\end{tabular}

Note: $* p<.05, * * p<.01, * * * p<.001$ 


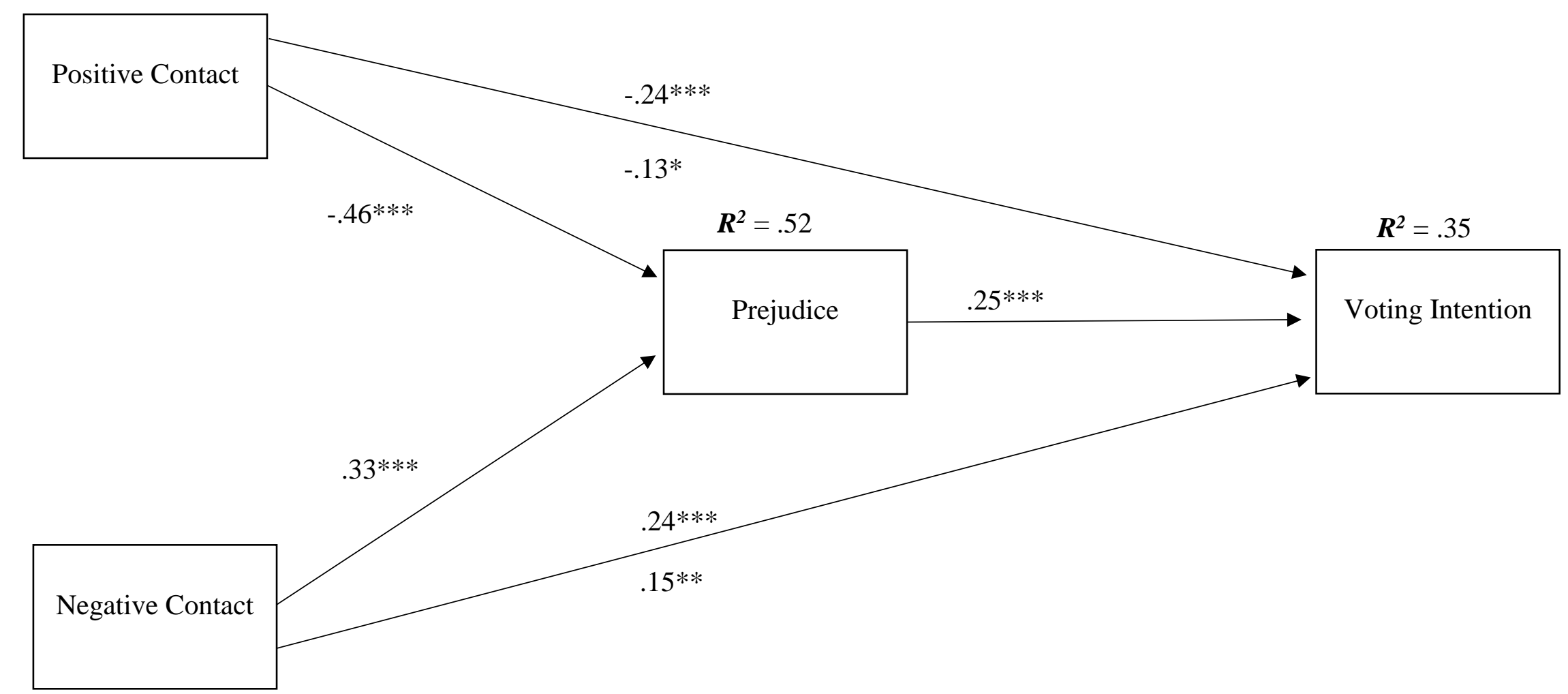

Figure 1: A mediational model of the relationships among positive and negative intergroup contact with EU immigrants and voting intentions, through anti-immigrant prejudice. Demographic variables (age, education and political conservatism) are included as covariates in the model. Note. Higher scores on the voting intention scale indicates a preference for Leave. Standardised coefficients are reported. The coefficient above the path from the independent variables to the dependent variable represents its effect without the mediator in the model, the coefficient below the path represents its effect when the mediator is included in the model $* p<.05$, ** $p<.01, * * * p<.001$ 